\title{
Socio-economic Background and Early Post-compulsory Education Pathways: A Comparison between Natives and Second-generation Immigrants in Switzerland
}

\author{
Francesco Laganà $^{1, \star}$, Julien Chevillard ${ }^{2}$ and Jacques-Antoine Gauthier ${ }^{1}$
}

\begin{abstract}
This article investigates the differences in post-compulsory education pathways between natives and second-generation immigrants in Switzerland. It analyses to which extent the socioeconomic background explains the different post-compulsory education trajectories of children of Swiss and second-generation immigrants. Using data from the Transition from Education to Employment survey (TREE), we use Optimal Matching Analysis to identify typical transitions encompassing the 7 years that follow the end of compulsory school and logistic regression to analyse the differences between native-born children and second-generation immigrants. In the first part of the article, we show that second-generation immigrants from low-skilled waves of migration are more likely to follow lower vocational tracks and to have an early transition into working class occupations. We also find that second-generation immigrants present higher likelihood of transition into 'Not in education, employment, or training' (NEET). In the second part of the article, we show that the early transition into working class occupations is entirely explained by socio-economic factors. We also demonstrate that, for the children of Portuguese, former-Yugoslav, Albanian, and Turkish immigrants, the socio-economic background plays a minor role in explaining the transitions into NEET. In this case, a disadvantage persists even after socio-economic background is taken into account in the model.
\end{abstract}

\section{Introduction}

Second-generation immigrants are often more disadvantaged compared with the native population with respect to labour market opportunities and educational achievements (Heath and Cheung, 2007). The present contribution will investigate this issue by focusing on the processes that lead to the production of second-generation disadvantages and the role played by socioeconomic background. To approach this topic, we adopt a longitudinal perspective that considers the specific paths following the end of compulsory education.

The main theoretical framework explaining the effect of social origin on the inequality of opportunities is represented by the Origin-Education-Destination (OED) framework (Erikson and Jonsson, 1996). This analytical framework has been adapted to the research on secondgeneration immigrants by adding the minority dimension to create the O(M)ED model (Kalter et al., 2007). The main advantage of this model is that by comparing different points in time (e.g., parent and respondent occupations), the model can be applied to cross-sectional data when biographical information regarding respondent social background is available.

This approach may appear suited to analyse previously structured inequalities or to study changes in inequalities among different cohorts; however, the method does not consider individual trajectories to a given occupational outcome (Abbott, 2001). Such trajectories reflect specific configurations of time-related constraints and

${ }^{1}$ Life Course and Inequality Research Centre (LINES), Institute of Social Sciences, University of Lausanne. Swiss National Centre of Competence in Research LIVES-Overcoming vulnerability: life course perspectives ${ }^{2}$ Life Course and Inequality Research Centre (LINES), Institute of Social Sciences, University of Lausanne ${ }^{*}$ Corresponding author. Institute of Social Sciences, University of Lausanne, CH-1015, Lausanne, Switzerland. Email: francesco.lagana@unil.ch

(C) The Author 2013. Published by Oxford University Press. All rights reserved.

For permissions, please e-mail: journals.permissions@oup.com. Submitted: July 2012; revised: April 2013; accepted: May 2013. 
opportunities allowing or prohibiting access to certain types of education and transitions into the labour market. From this perspective, a consideration of the chronological sequences of statuses at an individual level may represent a promising complementary approach to the standard framework.

Post-compulsory education pathways and transitions from school-to-work are of particular interest in the formation of inequalities. As disadvantages accumulate over a lifetime (Dannefer, 2003), a suboptimal start in the occupational arena often leads to a progressive worsening of the initial situation (Giudici and Gauthier, 2009). Given that time is a necessary component of life transitions (George, 1993), the longitudinal perspective allows for a better understanding of their dimensions as processes. The longitudinal framework is even more valuable when studying processes of second-generation immigrant social integration because the study of these processes naturally implies a lifetime approach (Wingens et al., 2011). Nonetheless, few studies have researched second-generation immigrants in a longitudinal setting. Starting from these considerations, the present study investigates the early integration pathways of secondgeneration immigrants in Switzerland. More specifically, this contribution addresses three research questions: (i) Do the post-compulsory education pathways between children of Swiss citizens and the children of immigrants differ? (ii) To what extent are such differences explained by social origins? (iii) Do differences exist between minority groups?

The case of Switzerland is relevant for three reasons. First, Switzerland has one of the greatest shares of second-generation immigrants in Europe (Marks, 2005). Second, Switzerland is a privileged site to study the effect of a highly stratified and selective educational system ${ }^{1}$ on the structure of social inequalities. Lastly, Switzerland is characterized by the presence of a highly diversified immigrant population in terms of geographical origin and socio-economic position.

\section{Second-generation Immigrants in Switzerland}

Switzerland has a long history as immigrant-receiving country. Since the end of Second World War, the Swiss labour market has been characterized by large waves of immigrant unskilled workers from Italy and Spain during the 1960s and from Portugal, former Yugoslavia, and Albania after the mid-1980s (Piguet, 2004). Swiss immigration history has also been characterized by highly skilled immigration flows from both neighbouring countries and worldwide because of the great concentration of many international firms and administrations headquarters.

The estimation of the size of the second-generation population varies according to definition criteria used. When individuals born in Switzerland with two foreignborn parents are considered, Marks (2005) estimated the proportion of second generations in Switzerland at $8 \%$ of the cohort that was 15 years of age in 2000. Using a different criterion-being born in Switzerland and having at least one parent born abroad-Bauer and Riphahn (2007: 127) estimated this incidence at $\sim 19.8 \%$ for all 17-year-old individuals. In an analysis based on Census data, Fibbi and Lerch (2007) estimated that 28\% of the population aged 15 to 24 years had foreign-born parents (without distinguishing the age of arrival in the host country). Of those, $\sim 6.9 \%$ are of former Yugoslav origin, $2 \%$ of Turkish origin, $2.4 \%$ of Portuguese background, and $4.9 \%$ of Italian origin. In the present manuscript, we consider second-generation immigrants to be all those individuals who arrived in Switzerland before the age of six and have two foreign-born parents. According to these criteria, the proportion of secondgenerations between 15 and 24 in 2009 was 18.9\%; 4\% had Italian or Spanish parents, and $9.2 \%$ had parents from Portugal, the Balkans, or Turkey ${ }^{2}$.

\section{Literature Review and Theoretical Model}

\section{Educational and Occupational Outcomes of Second-generation Immigrants}

Findings on ethnic minority educational achievement generally identify disadvantage between native population and second-generation immigrants. The most disadvantaged groups are from non-Western countries (Levels and Dronkers, 2008). Children of Turkish ancestry are the most disadvantaged in Belgium (Phalet et al., 2007), the Netherlands (van de Werfhorst and van Tubergen, 2007), and Norway (Fekjær, 2007). Similarly, young adults of North African origin are disadvantaged in France (Brinbaum and Cebolla-Boado, 2007). Yet, children of immigrants whose parents are from emigration-oriented European countries, such as Portugal, Spain, and Italy, show patterns similar to the native population. This is the case of Italians in Belgium (Phalet et al., 2007), Portuguese in France (Brinbaum and Cebolla-Boado, 2007), and former Yugoslavs in Germany (Kristen and Granato, 2007).

However, several studies found that certain secondgeneration groups show better educational attainment, such as Indians in Britain (Rothon, 2007) and Greeks 
and Portuguese in Germany (Kristen and Granato, 2007).

Similar patterns are found in labour market research (Heath et al., 2008). Considering the risk of unemployment, the literature shows that second-generations have fewer disadvantages in Australia, Canada, the United States, the United Kingdom, and Sweden, whereas greater disadvantages exist for second-generations in Belgium, France, Germany, and the Netherlands (Heath and Cheung, 2007). Research analysing occupational attainment found patterns similar to the majority population in Britain and Sweden, while systematic disadvantage was found in Germany for children of Turkish ancestry (Heath and Cheung, 2007).

In Switzerland, several studies suggested the presence of differences in educational attainment among youth in the first immigration waves compared with the children of immigrants who arrived in the previous two decades (Fibbi and Wanner, 2009). Fibbi and Lerch (2007) highlighted that $25 \%$ of young migrants from the SerboCroatian-speaking part of former Yugoslavia lack postsecondary degrees.

This negative picture is mirrored in the labour market position of youths with an immigrant background. Fibbi and Wanner (2009) showed that the risk of unemployment among foreign nationals between 15 and 24 is twice that of their Swiss peers, with a higher difference for children of more recent immigrants.

Research on educational attainment and labour market positioning of ethnic minorities primarily describes a disadvantage when compared with their national counter parts, with some noteworthy exceptions. In the following section, we will examine the reasons why socio-economic background should (or should not) mediate this difference.

\section{The Role of Socio-economic Background in the Differences Between Second-generation Immigrants and Natives}

The main mechanism proposed to explain differences in educational and occupational outcomes of second-generation immigrants is the Origin-Education-Destination model (OED) (see Heath and Brinbaum [2007]). According to this model, the disadvantage experienced by the second-generations is explained by the intergenerational transmission of parental resources. These resources can be related to material wealth (income), education, or skills, such as knowledge of the local educational system.

Erikson and Jonsson (1996) stressed that educational achievement depends on parental endowments and investments in their children. As education has a cost, 'the economic circumstances of the family of origin affect transition probabilities by influencing the costs of schooling' (p: 17).

Another important dimension of socio-economic background is parental education. Research showed that children with highly educated parents have linguistic and cognitive advantages and differently perceive the costs and benefits of education (Boudon, 1974). Parental education could be seen as a measure of cultural capital that is transmitted to the children through socialization and intended to provide advantages in learning ability and educational outcomes (Bourdieu and Passeron, 1990).

Second, highly educated parents tend to have a good understanding of the school system and are able to better guide their children's educational choices (Erikson and Jonsson, 1996).

Lastly, parental economic and educational capital could affect their children's aspirations and the perceived utility associated with a given educational choice (Boudon, 1974). According to the relative risk aversion theory, the decision for the children to continue or cease their education is based on the attempt to avoid downward social mobility. Consequently, children from the working class will stop their education relatively early and make an earlier labour market entry compared with children of the upper classes. The latter will pursue more education to attain the educational level required to avoid downward social mobility (Breen and Goldthorpe, 1997). Thus, we should expect a strong socio-economic background influence because second generations are children of immigrants that were assimilated in the lowest occupations of the host labour market. Therefore, these children would reach the same occupation of their parents with few years of schooling. In line with these theoretical insights, parental social class and education largely explain the disadvantage in the relative chance of attaining the $\mathrm{Abitur}^{3}$ of former Yugoslavs and Turkish in Germany (Kristen and Granato, 2007). Similarly, the disadvantages in Belgium tend to disappear for Italians and, to a smaller extent, for children of Moroccan ancestry (Phalet et al., 2007). In France, social background explains the overall disadvantage in test scores for children of Portuguese ancestry (Brinbaum and Cebolla-Boado, 2007). Socio-economic background explains half of the disadvantage of Turkish and Pakistani students in Norway (Feckjær, 2007) and in Britain (Rothon, 2007).

Although social origins play a major role in explaining most ethnic differences, there are certain notable exceptions. Literature showed that in some cases, the socio-economic background only partially explains the educational paths of second-generation immigrants. On 
the one hand, there could be a process of positive selection where immigrants encourage their children to have higher aspirations and better educational and occupational attainment (Chiswick, 1978). As the experience of migration often represents a project of intergenerational social mobility, parents of the second generations have higher expectations for their children (Zeroulou, 1988), and ethnic groups can associate different benefits with a given educational achievement and invest more in education. Alternatively, second-generation immigrants could be motivated to make more educational investments because they anticipate future discrimination in the labour market. Kristen and Granato (2007) found a persisting advantage for Portuguese in Germany after controlling for social origins. Similarly, Rothon (2007) found an advantage in second-generation immigrants for the children of Indian immigrants in Britain.

Some research found that the second-generation disadvantage persists after controlling for the class of origin. First, it is possible that not all immigrants of the first generation were positively selected. This could be the case for immigrants recruited to work in less skilled jobs, such as the Turkish in Belgium or the Italians in Germany. Another important factor could be knowledge of the host country language (Crul, 2000); poor language fluency of first-generation immigrants could have a negative effect on second-generation educational achievement. For example, van de Werfhorst and van Tubergen (2007) found that parental use of Dutch positively affected their children's test scores. This aspect could be important because the most recent waves of immigrants are less likely to be familiar with the host country's language.

Lastly, another possible explanation of second-generation disadvantage relates to the presence of ethnic discrimination. Swiss evidence of this issue is particularly interesting; using the practice testing procedure (Bovenkerk, 1992), Fibbi et al. (2006) showed the existence of discrimination against Turkish and Balkan young adults seeking to enter the labour market.

Although second-generation literature has extensively analysed the role of socio-economic background, there is a substantial lack of information regarding the influence of socio-economic dimensions on second-generations' school-to-work transitions. Rather than a mere retrospective linking of the explanandum (e.g., occupational status) with some antecedent factors (e.g., education), the longitudinal approach allows for the observation of the ways in which the state of individuals on a given property vary over time (e.g., variations in the education/occupation dimensions). Moreover, measurements of more than two time points make it possible to observe the differentiation of patterns in school-to-work transitions. This observation is an important aspect when studying ethnic minorities, as the integration process occurs over a lifetime, and the transition to work is important for labour market incorporation. In the following section, we will present our approach in more detail to shed light on those processes.

\section{Hypotheses}

Relating to possible explanatory mechanisms, we use the $\mathrm{O}(\mathrm{M}) \mathrm{ED}$ model as the main reference to formulate our hypothesis. Unlike the standard $\mathrm{O}(\mathrm{M}) \mathrm{ED}$ model, we consider our explanandum to be the different patterns from $\mathrm{E}$ (ducation) into $\mathrm{D}$ (estination).

Hypothesis I: We expect that second-generation immigrants are more likely to experience an earlier transition into the labour market or out of the school system compared with Swiss children.

Hypothesis II: As the most consistent portion of secondgeneration immigrants in Switzerland (Italian, Spanish, Portuguese, Balkan, and Turkish) originates from waves of less skilled immigration, we expect that their socioeconomic background represents an important factor in explaining the difference in post-compulsory education trajectories.

Hypothesis III: We expect to find smaller differences for the children of Spanish and Italian origins with respect to the Balkan, Turkish, and Portuguese second generations. Because the Italian and Spanish groups are more established in Switzerland, second generations from these groups should have more familiarity with Swiss society, educational system, and language. We expect that children of more recent immigration waves will experience more troubled post-compulsory school transitions because of less familiarity with the Swiss educational system and the lack of linguistic fluency. We lastly expect second-generation immigrants from countries that are not associated with unskilled migration will have a similar performances compared with their Swiss counterparts owing to higher positive selectivity.

\section{Research design}

\section{Data}

To address our research questions, we used data from the 'Transition from Education to Employment (TREE) survey (TREE, 2010)'. The initial sample of this 
longitudinal survey gathered 6,343 individuals who had completed their compulsory education and participated in the 'Program for International Student Assessment' (PISA) survey in 2000. Individuals were interviewed yearly between 2001 and 2007. Our sample is limited to those individuals who participated in the seven waves of the survey. Our final sample comprises 3,788 individuals, among whom 2,453 were born in Switzerland from Swiss parents; 590 arrived in Switzerland before the age of 6 and had at least one Swiss parent (second-and-a-half generations); 205 were second-generation minorities of Italian or Spanish origins; 182 were second-generation minorities of Portuguese, Balkan ${ }^{4}$, and Turkish origin; 149 were individuals from other countries not primarily associated with low-skilled immigration in Switzerland ${ }^{5}$; and 209 individuals were born to foreign parents who arrived in Switzerland after the age of 6 (first-generation immigrants). As in any longitudinal survey, attrition mechanisms caused a progressive reduction in the sample over time. This fact is especially important here because immigrants consistently show greater attrition rates than native-born citizens (Laganà et al., 2013). To overcome this problem, we used the specific longitudinal weights provided with the TREE data (Sacchi, 2008: 15).

\section{Analytical Strategy}

The research design involved three steps. We first created individual post-compulsory education trajectories by attributing a single educational and/or occupational status to each of the 7 years following the end of compulsory education. We then gathered these various sequences in homogeneous clusters according to their levels of similarity. These two first steps allowed for the identification of a typology of chronological post-compulsory education transitions, which took the form of a categorical variable that was used as a dependent variable in multivariate analysis to study the differences in postcompulsory school pathways between natives and second-generation immigrants.

Comparing Chronological Sequences of Statuses. We used Optimal Matching Analysis (OMA) to compare the individual trajectories outlined above. Introduced to sociology by Abbott (1983), this method allows for the computation of a measure of distance between two sequences of symbols (here representing educational and occupational position at each wave of the survey), according to the minimum (weighted) number of elementary operations of insertion, deletions, and substitutions (called costs) necessary to transform one sequence into the other. This number expresses the distance between the two sequences. Hence, more dissimilar sequences have greater distances. This operation was performed on all pairs of sequences present in the dataset. All of the pairwise distances were gathered in a distance matrix, which was used for the clustering procedure.

In the present manuscript, the $\mathrm{R}$ ( $\mathrm{R}$ core Team, 2011) package TraMineR (version 1.8, Gabadinho et al., 2011) was used to generate the pairwise optimal distances. Our treatment of the two parameters mentioned above (insertion/deletion and substitution costs) set the first to a value of one, while the substitution matrix was generated using the transition rates between the statuses used to form the sequences as observed in our data (Gauthier et al., 2009).

The individual sequences of post-compulsory education pathways were generated by attributing one of the nine educational or occupational statuses held by the respondents for the corresponding year to each of the 7 years throughout the observation period. With respect to education, we specifically considered the following statuses: A. Low Vocational (basic vocational apprenticeship-3 years after completing compulsory school); B. High Vocational (higher vocational training -5 years after completing compulsory school); C. General/ University (upper general secondary education and/or tertiary education); and D. Other education (training period, language study, holiday/stay, preliminary course, language course, and/or other undefined training).

For occupation, we recoded ISCO-88 into five categories: A. Higher Non-manual Occupations, with major groups 1 (legislators, senior officials, and managers), 2 (professionals), and 3 (technicians and associate professionals); B. Lower Non-manual Occupations, including major groups 4 (clerks) and 5 (service workers and shop and market sales workers); C. Higher Manual Occupations: major group 7 (craft and related trades workers); D. Lower Manual Occupations, consisting of major groups 6 (skilled agricultural and fishery workers), 8 (plant and machine operators and assemblers), and 9 (elementary occupations); and E. Not in Education, Employment or Training (NEET).

Clustering the Distance Matrix of Post-compulsory education Pathways. To identify typical post-compulsory school transitions, we ran a cluster analysis on the distance matrix produced by OMA using Ward's hierarchical cluster algorithm (Ward, 1963) ${ }^{6}$. One general issue associated with cluster analysis concerns the number of groups actually present in the data. From the indices provided in statistical literature (Milligan and Cooper, 1985), we selected the Silhouette Index, as available with the $\mathrm{R}$ package 'Flexible Procedures for Clustering (FPC, version 2.0.3)'.

Direct and Indirect Effects of Ethnic Minority Status on Types of Post-compulsory School Transitions. Once each 
respondent was associated with a typical post-compulsory school transition, the next step was the evaluation of the extent to which socio-economic background mediates the relationship between ethnic origins and cluster membership. We answered this question using logistic regression. However, a non-linear regression framework prohibits direct comparison of coefficients across models because the coefficients and the error variance cannot be separately identified. This problem is known as a scale identification issue (Winship and Mare, 1984). To disentangle the direct effect of ethnic membership from the effect mediated by parental socioeconomic background, we used the KHB method proposed by Karlson, Holm, and Breen (Karlson and Holm, 2011) using the KHB Stata package (version 2.4). Given the small sample size of certain groups, we checked for the robustness of the results using bootstrapping techniques to construct confidence intervals ${ }^{7}$. Moreover, when we had unbalanced distribution of our dependent variable, we compared our results with a rare event logistic regression model (King et al., 2001) to control for the bias introduced by unbalanced distribution in the dependent variable.

\section{Measurements}

The typology of post-compulsory school pathways represented our dependent variable. Regarding second-generations, we distinguished between three groups as shown in section " "Data" of "Research design"'.

Different measures have been proposed to serve as indicators of socio-economic background, such as social class (Ganzeboom et al., 1992), income (Solon, 1992), or education as a measure of cultural capital. Because this research tries to assess the overall mediating effect of socio-economic background, we chose the parental Index of Socio-economic status (ISEI; Ganzeboom et al., 1992). This index is a by-product of the mean educational and income levels for each occupation. The household ISEI is defined as the highest ISEI of the parents.

All the models have been controlled for gender, region of residence in Switzerland, and number of siblings ${ }^{8}$.

\section{Results}

\section{Description of the Post-compulsory Education Pathways}

We chose the number of clusters stemming from the distance matrix of individual sequences of post-compulsory education pathways according to the average silhouette index value associated with a given cluster solution (Kaufman and Rousseeuw, 1990). This index represents a measure of how a given point in a matrix is similar to points in its own cluster compared with points in other clusters. We evaluated different solutions, ranging from 4 to 20 clusters (see Figure Al in the Appendix for more details), and we chose the solution that corresponds to 10 clusters and represents the highest silhouette value.

Figure 1 displays the density plot for the 10 clusters, and Table Al in the appendix shows the Pearson residuals associated with the most discriminating subsequences ${ }^{9}$ in each cluster. The Pearson residuals represent the difference between the observed and expected theoretical frequency of a given subsequence under the case of independence between clusters and the subsequence $^{10}$. Thus, a higher Pearson residual indicates a greater transition contribution to the cluster. Hence, this measure allows for a better interpretation of the transitions represented in each cluster.

The advantage of this more explorative approach is to draw the different trajectories leading to the formation of inequalities in occupational attainment by directly including information on the link between education and work.

In an overall view, the 10 clusters can be considered as specifications of five large families of trajectories, as shown in Table 1. The first group gathers the transitions from general education into university (Cluster 1). This type of transition is right censored; we do not observe the occupational outcome, but we may suppose that it represents the cluster of trajectories leading to the highest socio-economic status. The second group represents the transitions from low vocational education into high vocational education (Cluster 2) or general education (Cluster 3). This group represents paths of upward educational mobility. The third group of clusters contains the atypical educational transitions (Cluster 4), primarily represented by individuals who remain in low vocational education or experience downward educational mobility (Cluster 5). The fourth family brings together transitions from low vocational education into the labour market ${ }^{11}$ and represents school-to-work transitions. Lastly, the fifth group represents a small cluster of transitions into NEET (Cluster 10).

\section{How do Second-generation Immigrants and Children of Native-born Citizens Differ in Early Pathways of Post-compulsory Education?}

Table 2 presents the cluster composition by ethnic group. The table shows that the different groups are unevenly distributed between clusters. The main 

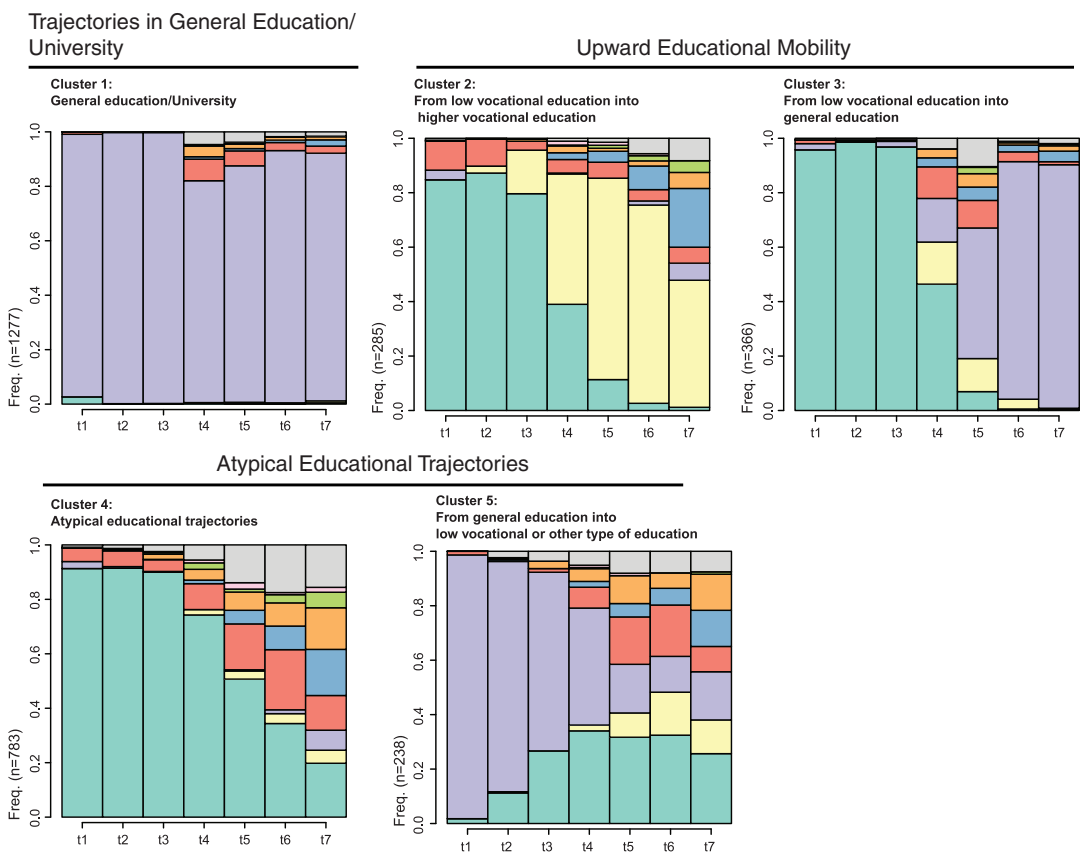

From Low Vocational Education into Labour Market
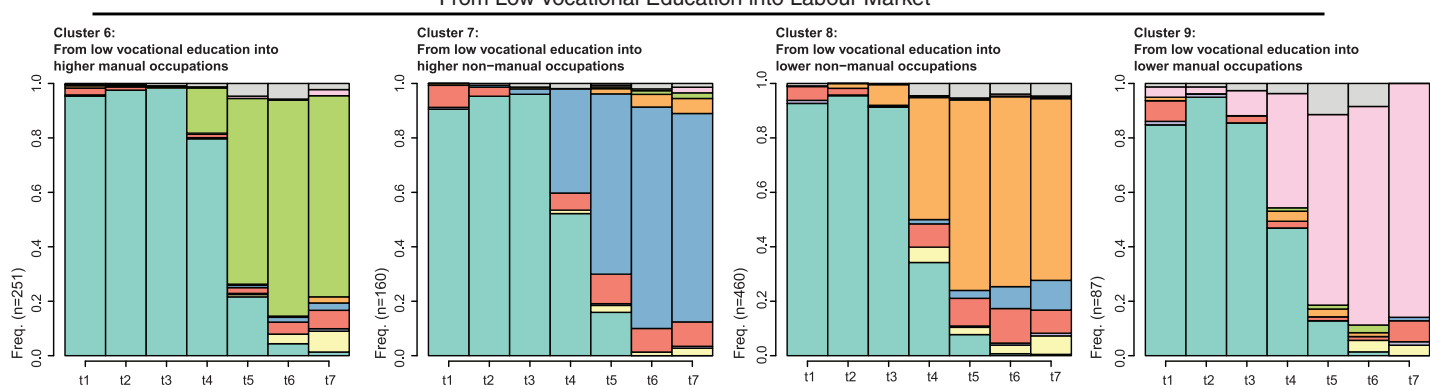

From Low Vactional Education into

Not Education Employment or Training

Cluster 10:

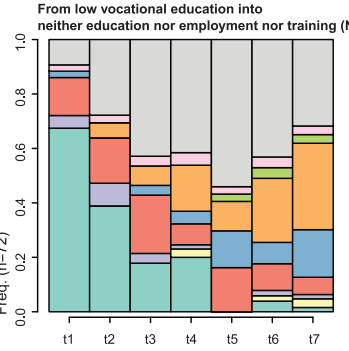

$\square$ Low Vocational

$\square$ High Vocational

$\square$ General/University

$\square$ Other formation

$\square$ Higher non manual occupations

$\square$ Lower non manual occupations

- Higher manual occupations

$\square$ Lower manual occupations

$\square$ Not in education, employment or training

Figure 1 Distribution of the states in each of the 10 clusters. Source: Our elaboration on TREE data

difference emerges when considering the General Education/University cluster, which has a clear overrepresentation of second generations from 'Other countries' (46.31\%) and Swiss (31.84\%). The table shows an under-representation of Portuguese, Balkan, and Turkish second generations (19.78\%). These last groups appear to be over-represented in the upward educational transitions (Cluster 2), transitions into the labour market (Cluster 8), and NEET (Cluster 10).

These first impressions are further corroborated by Table 3, where we present the average partial effects, which are estimated from binomial logistic regressions, 


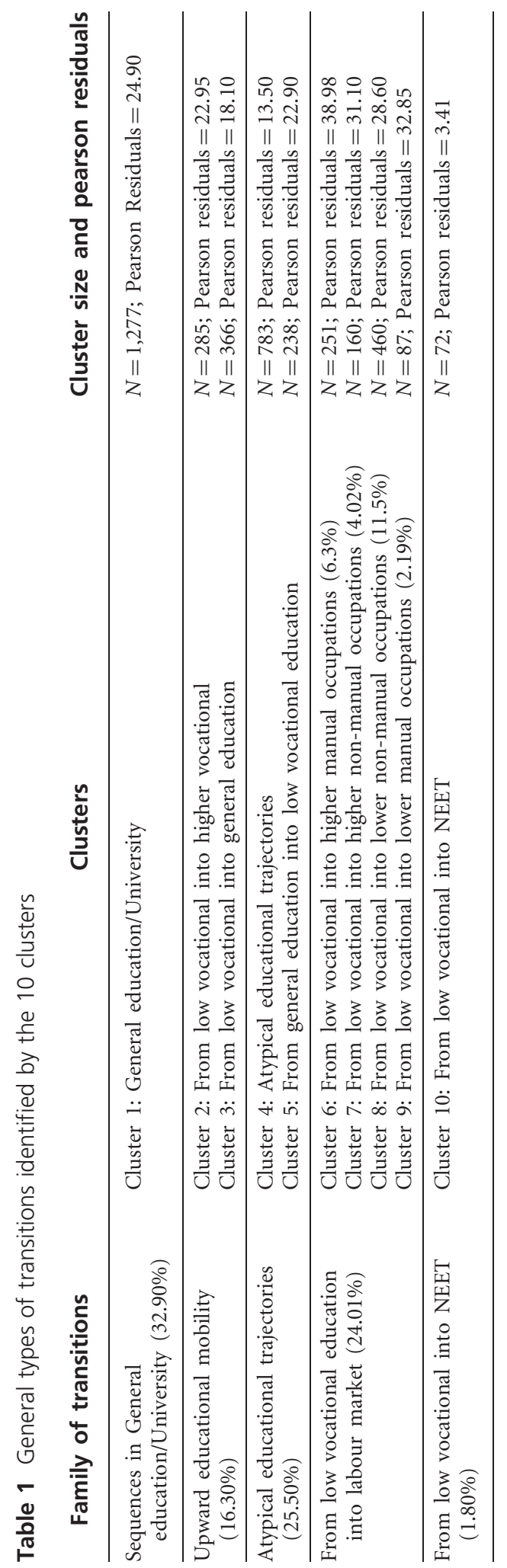

on the probability of belonging to each type of trajectory compared with experiencing trajectories in the General Education/University type. The table reveals that the difference between Swiss children and second generations is significant for the upward educational transitions (Cluster 2), the atypical educational transitions (Cluster 4), the transitions into lower non-manual occupations (Cluster 8), and transitions into NEET (Cluster 10).

Analysis of the upward educational transitions (Cluster 2 and Cluster 3) shows that greater probability is associated to Portuguese, Turkish, and Balkan secondgeneration group in experiencing these types of mobility.

Considering atypical educational trajectories, Table 3 suggests a greater probability for Italian, Spanish, Portuguese, Turkish, and Balkan minorities to experience transitions that characterize this cluster. Similarly, with respect to the pathways from school to labour market, children of Italian and Spanish immigrants are more likely than Swiss children to experience transitions into lower non-manual positions (Cluster 8).

The difference between native-born children and second-generation immigrants is larger when considering the transition from low vocational education into NEET (Cluster 10). The difference is particularly pronounced for the children of Italian, Spanish, Turkish, Balkan, and Portuguese immigrants as well as first-generation immigrants.

Table 3 shows additional differences among secondgenerations immigrants; considering transitions toward lower non-manual occupations (Cluster 8), the group from 'Other countries' has a lower probability of experiencing transitions that characterize this cluster. A similar trend, suggesting differentiation between trajectories of second-generation immigrants from 'Other countries' and those originating from the low-skilled waves of immigration, is shown for the other types of transitions. These first results appear to be in agreement with the argument of positive selection of migrants from 'Other countries'.

\section{Does the Socio-economic Background Explain the Difference in Early Post-compulsory Education Pathways Between Second-generation Immigrants and Natives?}

To address this question, we decomposed the total effect of minority membership on the post-compulsory education pathways into an indirect effect that is mediated by socio-economic origins and the direct effect of second-generation membership. To shorten the 
Table 2 Distribution of Swiss children and ethnic minority by cluster and main type of transitions (row percentages)

\section{General Upward Education/ educational University

Atypical
educational
trajectories

From low
vocational
education
into labour

From low $\mathbf{N}$ vocational education into NEET market

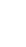

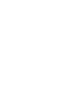

\begin{tabular}{|c|c|c|c|c|c|c|c|c|c|c|c|}
\hline \multirow[b]{2}{*}{ Clusters } & \multirow[b]{2}{*}{$\mathrm{Cl} 1$} & & & & \multirow[b]{2}{*}{$\mathrm{Cl} 10$} & \\
\hline & & $\mathrm{Cl} 2$ & $\mathrm{Cl} 3$ & $\mathrm{Cl} 4$ & $\mathrm{Cl} 5$ & $\mathrm{Cl} 6$ & $\mathrm{Cl} 7$ & $\mathrm{Cl} 8$ & $\mathrm{Cl9}$ & & \\
\hline Swiss & 31.84 & 7.75 & 9.78 & 18.55 & 5.79 & 6.97 & 4.57 & 11.46 & 2.49 & .82 & 2453 \\
\hline Second and a half generation & 40.17 & 4.07 & 8.14 & 20.17 & 6.44 & 3.39 & 2.37 & 11.19 & 1.36 & 2.71 & 590 \\
\hline Other countries & 46.31 & 6.71 & 7.38 & 22.82 & 7.38 & 2.68 & 0.67 & 2.68 & 1.34 & 2.01 & 149 \\
\hline Italian and Spanish & 25.37 & 5.85 & 7.80 & 25.85 & 7.80 & 5.85 & 1.95 & 15.12 & 1.46 & 2.93 & 205 \\
\hline Portuguese/Balkan/Turkish & 19.78 & 11.54 & 8.24 & 21.43 & 6.59 & 7.69 & 4.40 & 13.19 & 2.75 & 4.40 & 182 \\
\hline First-generation immigrant & 18.66 & 5.74 & 8.13 & 21.05 & 3.83 & 8.61 & 5.26 & 19.62 & 3.35 & 5.74 & 209 \\
\hline Tota & 32.0 & 7.10 & 9.16 & 19.64 & 5.99 & 6.31 & 3.96 & 11.80 & 2.27 & 1.72 & 3788 \\
\hline$N$ & 1214 & 269 & 347 & 744 & 277 & 239 & 150 & 447 & 86 & 65 & \\
\hline
\end{tabular}

Pearson's Chi-squared test with simulated P-value (2000 replications): $175.076 \mathrm{P}-$ value $=0.000$.

Source: Our elaboration on TREE data.

presentation of the results, we only focus on the types of transitions where we found significant differences between second-generation minorities and Swiss, namely, in clusters $2,4,8$, and 10 , each of which represents one family of clusters as summarized in Table 1 . In Table 4 , we decomposed the total effect presented in Table 3 into a direct effect and an indirect effect representing the part of the total effect mediated by socio-economic background. As in Table 3, the models are binomial logistic regressions where the reference category is General Education/University trajectories (Cluster 1). In addition, we present the incidence of direct and indirect effects on the total relationship.

The models show that socio-economic background plays a major role in the transitions toward lower nonmanual positions, atypical educational trajectories, and upward educational mobility.

Considering transitions from low vocational education into lower non-manual occupations (Cluster 8), socioeconomic background explains $68.6 \%$ of the total relationship for the Italian or Spanish second-generation immigrants and the entire effect on the children of Balkan, Turkish, and Portuguese immigrants. After the introduction of the ISEI, the ethnic minority effect is no more significant for both minority groups. There is, however, a significant direct effect for the second-generation immigrants from 'Other countries'. Even after controlling for socio-economic background, these individuals are less likely to experience transitions toward lower non-manual positions, indicating a relative advantage in this group.
Considering the atypical educational transitions (Cluster 4 ), the socio-economic background explains $\sim 73 \%$ of the higher likelihood of Italian and Spanish children in experiencing this transition; again, there is no more significant ethnic minority effect after ISEI is controlled.

Additionally, the transition toward higher vocational education (Cluster 2) is entirely explained by socioeconomic background.

According to the $\mathrm{O}(\mathrm{M}) \mathrm{ED}$ model, most of the disadvantages of second-generation immigrants are mediated by the position of their parents in the Swiss social stratification. However, after controlling for socioeconomic background, some second generations experience certain advantages (e.g., second-generation immigrants from 'Other countries').

Therefore, these first results indicate that, as long as we consider whole transitions into the labour market or educational mobility patterns, the model that best represents ethnic inequalities is the inter-generational transmission of the parental socio-economic status. Therefore, our results confirm the findings in other European countries.

The picture substantially changes when considering the transitions into NEET (Cluster 10). Here, the mediating effect of socio-economic background for Portuguese, Balkan, and Turkish second-generation immigrants appears to be weak, and a significant effect of minority membership remains. For this group, socioeconomic status mediates only $35.4 \%$ of the total effect, suggesting that disadvantage is only partially explained by socio-economic background. 
Table 3 Total effects from the binomial logistic regressions for the probability of experiencing transitions in each of the 10 clusters instead of cluster 1 (General Education/University). (Average Partial Effects and bootstrapped standard errors [1000 replications])

\begin{tabular}{|c|c|c|c|c|c|c|c|c|}
\hline & \multicolumn{2}{|c|}{$\begin{array}{c}\text { Cluster 2: } \\
\text { From low vocational into } \\
\text { higher vocational education }\end{array}$} & \multicolumn{2}{|c|}{$\begin{array}{c}\text { Cluster 3: } \\
\text { From low vocational into } \\
\text { general education }\end{array}$} & & & & \\
\hline & APE & SE & APE & SE & & & & \\
\hline \multicolumn{9}{|l|}{ Swiss (Ref.) } \\
\hline Second and a half generation & $-0.105^{\star *}$ & 0.033 & $-0.054 \dagger$ & 0.030 & & & & \\
\hline Other countries & -0.038 & 0.055 & $-0.105 \dagger$ & 0.057 & & & & \\
\hline Italian/Spanish & 0.025 & 0.050 & 0.021 & 0.050 & & & & \\
\hline Portuguese/Balkan/Turkish & $0.130^{\star *}$ & 0.041 & 0.057 & 0.055 & & & & \\
\hline First generation immigrants & 0.030 & 0.051 & 0.062 & 0.06 & & & & \\
\hline $\mathrm{N}$ & 1443 & & 1525 & & & & & \\
\hline \multirow[t]{3}{*}{ Pseudo $\mathrm{R}^{2}$} & 0.04 & & 0.02 & & & & & \\
\hline & \multicolumn{2}{|c|}{$\begin{array}{c}\text { Cluster 4: } \\
\text { Atypical trajectories in } \\
\text { low vocational education }\end{array}$} & \multicolumn{2}{|c|}{$\begin{array}{l}\text { Cluster 5: } \\
\text { From general education } \\
\text { into low vocational } \\
\text { education }\end{array}$} & & & & \\
\hline & APE & SE & APE & SE & & & & \\
\hline \multicolumn{9}{|l|}{ Swiss (Ref.) } \\
\hline Second and a half generation & -0.007 & 0.028 & -0.022 & 0.027 & & & & \\
\hline Other countries & -0.039 & 0.049 & -0.032 & 0.046 & & & & \\
\hline Italian/Spanish & $0.145^{\star *}$ & 0.047 & 0.057 & 0.043 & & & & \\
\hline Portuguese/ Balkan /Turkish & $0.121^{\star}$ & 0.057 & 0.048 & 0.054 & & & & \\
\hline First generation immigrants & $0.191^{* *}$ & 0.053 & 0.005 & 0.068 & & & & \\
\hline $\mathrm{N}$ & 1895 & & 1402 & & & & & \\
\hline Pseudo $\mathrm{R}^{2}$ & 0.02 & & 0.02 & & & & & \\
\hline \multirow[t]{2}{*}{ From low vocational into: } & \multicolumn{2}{|c|}{$\begin{array}{c}\text { Cluster 6: } \\
\text { Higher manual occupations }\end{array}$} & \multicolumn{2}{|c|}{$\begin{array}{l}\text { Cluster 7: } \\
\text { Higher non-manual } \\
\text { occupations }\end{array}$} & \multicolumn{2}{|c|}{$\begin{array}{l}\text { Cluster 8: } \\
\text { Into lower non manual } \\
\text { occupations }\end{array}$} & \multicolumn{2}{|c|}{$\begin{array}{l}\text { Cluster 9: } \\
\text { Into lower manual } \\
\text { occupations }\end{array}$} \\
\hline & APE & SE & APE & SE & APE & SE & APE & SE \\
\hline \multicolumn{9}{|l|}{ Swiss (Ref.) } \\
\hline Second and a half generation & $-0.066^{\star}$ & 0.027 & $-0.058^{\star}$ & 0.028 & -0.011 & 0.027 & -0.024 & 0.023 \\
\hline Other countries & $-0.110^{\star}$ & 0.051 & $-0.188^{\star \star}$ & 0.045 & $-0.282^{\star \star}$ & 0.085 & -0.039 & 0.028 \\
\hline Italian/Spanish & 0.054 & 0.033 & -0.036 & 0.053 & $0.134^{\star *}$ & 0.044 & -0.004 & 0.033 \\
\hline Portuguese/Balkan/Turkish & $0.077 \dagger$ & 0.043 & 0.047 & 0.044 & $0.136^{\star *}$ & 0.049 & 0.024 & 0.029 \\
\hline First generation immigrants & 0.009 & 0.038 & $0.078^{\star}$ & 0.039 & $0.259^{* *}$ & 0.043 & $0.058 \dagger$ & 0.032 \\
\hline $\mathrm{N}$ & 1410 & & 1327 & & 1618 & & 1263 & \\
\hline Pseudo $\mathrm{R}^{2}$ & 0.21 & & 0.05 & & 0.07 & & 0.11 & \\
\hline
\end{tabular}

\section{Cluster 10:}

From low vocational

into NEET

APE SE

Swiss (Ref.)

Second and a half generation $\quad 0.041^{* *} \quad 0.016$

Other countries $\quad 0.020 \quad 0.024$

Italian/Spanish $\quad 0.061^{*} \quad 0.026$

Portuguese/ Balkan /Turkish $\quad 0.079^{* *} \quad 0.025$

First generation immigrants $\quad 0.120^{* *} \quad 0.024$

$\mathrm{N}$

Pseudo $\mathrm{R}^{2} \quad 0.11$

Controlled for: Gender, number of siblings and zone of residence in Switzerland.

Sig. levels: $\dagger \mathrm{P}<0.10 ;{ }^{*} \mathrm{P}<0.05 ;{ }^{*} \mathrm{P}<0.01$.

Source: our elaboration on TREE data. 
Table 4 Direct effect and indirect effect (mediated via ISEI) of ethnic minority membership from the binomial logistic regressions for the probability of experiencing transitions in Cluster 2, 4, 8, and 10 instead of Cluster 1 (General Education/University)—only clusters with significant differences in Table 3. (Average Partial Effects and bootstrapped standard errors [1000 replications])

\begin{tabular}{|c|c|c|c|c|c|c|}
\hline \multirow{2}{*}{ Cluster 2: Upward educational mobility } & \multicolumn{2}{|c|}{ Direct } & \multicolumn{2}{|c|}{ Indirect } & \multirow{2}{*}{$\begin{array}{l}\text { Direct } \\
\%\end{array}$} & \multirow{2}{*}{$\begin{array}{l}\text { Indirect } \\
\quad \%\end{array}$} \\
\hline & APE & SE & APE & SE & & \\
\hline \multicolumn{7}{|l|}{ Swiss (Ref.) } \\
\hline Second and a half generation & $-0.093^{* *}$ & 0.032 & -0.012 & 0.027 & 88.57 & 11.43 \\
\hline Other countries & -0.020 & 0.052 & -0.018 & 0.027 & 52.63 & 47.37 \\
\hline Italian/Spanish & -0.024 & 0.048 & $0.049 \dagger$ & 0.028 & -96.00 & 196.00 \\
\hline Portuguese/Balkan/Turkish & 0.039 & 0.041 & $0.091^{* *}$ & 0.029 & 30.00 & 70.00 \\
\hline First-generation immigrants & -0.030 & 0.052 & $0.060^{*}$ & 0.028 & -100.00 & 200.00 \\
\hline$N$ & \multirow{2}{*}{\multicolumn{6}{|c|}{$\begin{array}{l}1443 \\
0.10\end{array}$}} \\
\hline Pseudo $\mathrm{R}^{2}$ & & & & & & \\
\hline Cluster 4: Atypical educational transitions & APE & SE & APE & SE & $\%$ & $\%$ \\
\hline \multicolumn{7}{|l|}{ Swiss (Ref.) } \\
\hline Second and a half generation & 0.001 & 0.028 & -0.009 & 0.039 & -14.29 & 128.57 \\
\hline Other countries & -0.025 & 0.047 & -0.013 & 0.039 & 64.10 & 33.33 \\
\hline Italian/Spanish & 0.039 & 0.048 & $0.106^{\star *}$ & 0.040 & 26.90 & 73.10 \\
\hline Portuguese/Balkan/Turkish & -0.042 & 0.057 & $0.163^{\star \star}$ & 0.041 & -34.71 & 134.71 \\
\hline First-generation immigrants & 0.073 & 0.055 & $0.117^{* *}$ & 0.040 & 38.22 & 61.26 \\
\hline$N$ & \multirow{2}{*}{\multicolumn{6}{|c|}{$\begin{array}{l}1895 \\
0.11\end{array}$}} \\
\hline Pseudo $\mathrm{R}^{2}$ & & & & & & \\
\hline Cluster 8: Lower non-manual occupations & APE & SE & APE & SE & $\%$ & $\%$ \\
\hline \multicolumn{7}{|l|}{ Swiss (Ref.) } \\
\hline Second and a half generation & 0.006 & 0.025 & -0.017 & 0.040 & -54.55 & 154.55 \\
\hline Other countries & $-0.231^{* *}$ & 0.087 & -0.050 & 0.040 & 81.91 & 17.73 \\
\hline Italian/Spanish & 0.042 & 0.045 & $0.092^{*}$ & 0.040 & 31.34 & 68.66 \\
\hline Portuguese/Balkan/Turkish & 0.006 & 0.052 & $0.130^{\star *}$ & 0.041 & 4.41 & 95.59 \\
\hline First-generation immigrants & $0.122^{\star \star}$ & 0.046 & $0.136^{\star *}$ & 0.041 & 47.10 & 52.51 \\
\hline$N$ & \multirow{2}{*}{\multicolumn{6}{|c|}{$\begin{array}{l}1618 \\
0.18\end{array}$}} \\
\hline Pseudo $\mathrm{R}^{2}$ & & & & & & \\
\hline Cluster 10: Into NEET & APE & SE & APE & SE & $\%$ & $\%$ \\
\hline \multicolumn{7}{|l|}{ Swiss (Ref.) } \\
\hline Second and a half generation & $0.045^{* *}$ & 0.016 & -0.004 & 0.010 & 109.76 & -9.76 \\
\hline Other countries & 0.026 & 0.024 & -0.006 & 0.010 & 130.00 & -30.00 \\
\hline Italian/Spanish & $0.046 \dagger$ & 0.025 & 0.015 & 0.010 & 75.41 & 24.59 \\
\hline Portuguese/Balkan/Turkish & $0.051^{\star}$ & 0.025 & $0.028^{*}$ & 0.012 & 64.56 & 35.44 \\
\hline First-generation immigrants & $0.099^{* *}$ & 0.024 & $0.021 \dagger$ & 0.011 & 82.50 & 17.50 \\
\hline$N$ & \multicolumn{6}{|c|}{1240} \\
\hline Pseudo $\mathrm{R}^{2}$ & & & 0.17 & & & \\
\hline
\end{tabular}

Controlled for: gender, number of siblings, and zone of residence in Switzerland. Sig. levels: $\uparrow \mathrm{P}<0.10 ;{ }^{*} \mathrm{P}<0.05 ;{ }^{* *} \mathrm{P}<0.01$.

Source: our elaboration on TREE data. 
If the strong effect of socio-economic background, as mediator, allows for us to identify some range of mechanisms of inequality formation in the paths following post-compulsory education, this last result is quite puzzling: why should second-generations from the Balkans and Portugal experience high probability in the transition into NEET?

There are at least two possible explanations for this finding. We can first hypothesize a mechanism of 'downward assimilation' similar to the process described by Portes and Rumbaut (2001). In this case, we should expect a future integration in the secondary labour market with a fragmented employment career. Another possible explanation could be linked to the lack of resources-such as linguistic skills-that prevent these students from experiencing more 'standardized' paths. An argument that might support this view is the finding that children of most recent immigration waves are more exposed to this type of transition. Therefore, their contact with the host society could be less mediated by the family's environment compared with children of better-settled immigrant groups.

\section{Discussion}

This study proposed a typology of early post-compulsory education pathways in Switzerland and investigated the differences between natives and second-generation immigrants.

Our starting point was the integration of the OED framework with the longitudinal analysis of school-towork transitions. Considering the temporal patterns linking Education-to-Destination, this approach allows for us to investigate the different routes that lead to a given occupation (Bühlmann, 2010). We showed the processes of differentiation over time in individual trajectories and focused on a lifetime period that is of primary importance for further educational and occupational attainment. The focus on the dynamics by which diverging trajectories are shaped gives us clearer insights into the processes of inequality formation. This approach additionally allowed for us to identify several patterns of early integration. These patterns are not clearly visible in the standard OED model, where the explanans (e.g., the probability of tertiary education or employment) is set by the researcher and the probability of obtaining a given attribute (e.g., type of occupation) is often modelled rather than focusing on the process leading to that given attribute.

In a second step, we explored the differences between second-generation immigrants and Swiss children on the paths of integration into Swiss society.
Our results showed that second-generation immigrants are more likely to experience early transitions from low vocational educational tracks either into the labour market or NEET. However, not all secondgenerations follow the same route. Second generations from countries that are not primarily associated with low skilled immigration (the category 'Other countries') are more likely to be enrolled in higher tracks than secondgenerations originating from the less skilled waves of migration. Furthermore, children of Portuguese, Balkan, and Turkish origins are more likely to experience paths of mobility from low vocational education to high vocational education and early transitions into the labour market.

We lastly observed how socio-economic factors mediate the differences between Swiss and ethnic minorities in the type of transitions in which individuals are engaged.

With respect to school-to-work transitions and upward educational transitions, the results showed that the differences between ethnic groups actually reflect a disadvantage in terms of socio-economic origin. Therefore, Switzerland does not represent a peculiar case within the European context, and our results are in line with the European literature (Heath et al., 2008). We conclude that the $\mathrm{O}(\mathrm{M}) \mathrm{ED}$ model represents a powerful tool to explain this type of transition. Our results are consistent with findings in the Swiss context. OECD (2005) noted that Switzerland represents one of the countries where the inter-generational transmission of education is the strongest. However, the longitudinal approach used in our research clearly presented the different ways that educational inequalities lead to occupational inequalities. The study showed the interplay of socio-economic background and ethnic origins in determining the different routes taken by second-generation minorities.

Considering early transitions into work, the present study demonstrated that one way to enhance equality between Swiss children and second-generations could be to focus on educational policies aiming at equalising access to education for pupils of different socio-economic backgrounds. Swiss research (Stadelmann-Steffen, 2012) has shown that educational policies moderate the relationship between social background and educational achievement; cantons with high educational expenditures have less educational inequality.

However, our examination of the paths towards Not in Education, Employment, or Training (NEET) showed that a net effect of minority status still persists after controlling for socio-economic background (Cluster 10); this result represents a dimension that is specific to ethnic minorities from Portugal, the Balkans, and Turkey. In this case, we suggested that factors beyond the ethnic dimension, such as the linguistic skills of the second-generation immigrants' 
parents and their integration of the host society, influenced the result.

We lastly showed results on the differentiation of ethnic minority groups. A significant direct effect persists for second-generation minorities stemming from highskilled migration (the category 'Other countries') when considering the transitions toward lower non-manual positions versus General/University educational paths. This result suggests that independent of social origin, this type of second-generation migrants tends to avoid lower vocational paths. Second, a consideration of transitions into NEET indicates that socio-economic background explains the total disadvantage of Italian and Spanish second generations, while residual disadvantage remains for the Portuguese, Balkans, and Turkish.

There are, however, three main limits in the present study that future research should investigate. We did not distinguish between the different mechanisms through which social background operates (e.g., cultural capital, economic capital, and aspirations). In addition, we only focused on a brief observational period. Further research should extend the observation to the point in time when all education-to-work transitions are completed. Lastly, studies directly targeting second-generation immigrants are needed to overcome the problem of small sample size, which frequently influences the researcher to tradeoff between a rough aggregation of the minority groups and the statistical robustness of the results.

\section{Notes}

1. In the Swiss education system, children are enrolled in compulsory education from the ages of 6 to 15 years. Afterward, the educational paths diverge into 2- to 4year apprenticeships that prepare students for vocational careers or a general formation that matriculates into universities. Therefore, Switzerland is characterized by both high selectivity and segmentation. Beginning in their secondary education, pupils are divided into different educational tracks according to their educational performances. After this first selection, pupils are divided between the majority, who will follow a vocational education, and the highly selected minority ( $\sim 20 \%$ of the pupils), who will stay on the general track (Meyer, 2009).

2. Source: our elaboration on Swiss Labour Force Data.

3. In German educational system, the Abitur degree is the equivalent of a 'high school diploma'.

4. We include respondents of Former Yugoslav and Albanian origins in the Balkan minority category.
5. The category 'Other countries' tries to capture the effect of the more skilled migration component. The most represented nationalities are Germans, Austrian, French, Belgian, and a residual category of individuals originating from other non-specified countries.

6. The Ward's hierarchical cluster algorithm, joining together less distant groups at each step and minimizing the within-cluster discrepancy, maximizes the between-clusters difference.

7. The significance levels from non-bootstrapped models are largely similar to the significance levels obtained with bootstrapping.

8. We hypothesize that a higher number of siblings results in a lower amount of income (or resources) available for educational investment in each child.

9. A subsequence is represented as a sequence of statuses within each cluster. A subsequence could be a change between statuses (in Table Al the change from Low Vocational Education into High Vocational Education) or permanence in the same status. For example, the sequence L/V in Table Al indicates sequences of individuals that stay in a low vocational educational program for 7 years.

10. Generally, the criterion for identifying a significantly discriminating sequence is the size and sign of the residuals. Residuals higher than 2 indicate that the subsequence is significantly present in the cluster, while residuals lower than [minus] 2 suggest an underrepresentation of a subsequence in the cluster.

11. More specifically, into skilled working class (Cluster 6), higher non-manual positions (Cluster 7), lower non-manual positions (Cluster 8), and lower nonmanual occupations (Cluster 9).

\section{Acknowledgements}

We thank the two anonymous reviewers for their helpful comments. This publication is part of the research work conducted at the Swiss National Centre of Competence in Research LIVES - Overcoming vulnerability: life course perspectives, which is financed by the Swiss National Science Foundation.

\section{References}

Abbott, A. (1983). Sequences of Social events: concepts and methods for the analysis of order in social processes. Historical Methods, 1, 129-147. 
Abbott, A. (2001). Time Matters. On Theory and Method. Chicago: University of Chicago Press.

Bauer, P. and Riphahn, R. T. (2007). Heterogeneity in the intergenerational transmission of educational attainment: evidence from Switzerland on natives and second-generation immigrants. Journal of Population Economics, 20, 121-148.

Bourdieu, P. and Passeron, J. C. (1990). Reproduction in Education, Society, and Culture. London: SAGE.

Boudon, R. (1974). Education, Opportunity, and Social Inequality: Changing Prospects in Western Society. New York: Wiley.

Bovenkerk, F. (1992). A manual for International Comparative Research on Discrimination on the Grounds of 'Race' and Ethnic Origin. Geneva: ILO.

Breen, R. and Goldthorpe, J. H. (1997). Explaining educational differentials: towards a formal rational action theory. Rationality \& Society, 9, 275-305.

Brinbaum, Y. and Cebolla-Boado, H. (2007). The school careers of ethnic minority youth in France: success or disillusion? Ethnicities, 7, 445-476.

Bühlmann, F. (2010). Routes into the British service class: feeder logics according to gender and occupational groups. Sociology, 44, 195-212.

Chiswick, B. R. (1978). The effect of Americanization on the earnings of foreign born men. Journal of Political Economy, 86, 897-921.

Crul, M. (2000). Breaking the circle of disadvantage. Social mobility of second-generation Moroccans and Turks in the Netherlands. In Vermeulen, H. and Perlman, J. (Eds.), Immigrants, Schooling and Social Mobility. Does Culture Make a Difference?. London: Macmillan, pp. 225-244.

Dannefer, D. (2003). Cumulative advantage/disadvantage and the life course: cross-fertilizing age and social science theory. Journal of Gerontology, 58b, S327-S337.

Erikson, R. and Jonsson, J. O. (Eds.) (1996). Can Education be Elqualized? The Swedish Case in Comparative Perspective. Boulder, CO: Westview.

Fekjær, S. N. (2007). New differences, old explanations: Can educational differences between ethnic groups in Norway be explained by social background? Ethnicities, 7, 367-389.

Fibbi, R., Lerch, M. and Wanner, P. (2006). Unemployment and discrimination against youth of immigrant origin in Switzerland: when the name makes the difference. Journal of International Migration and Integration, 7, 351-366.

Fibbi, R. and Lerch, M. (2007). Transition à la vie adulte des jeunes issus de la migration: dynamique intergénérationnelle et conséquences sociales. Neuchâtel: Swiss Forum for Migration and Population Studies.
Fibbi, R. and Wanner, P. (2009). Children of Immigrant Families in Switzerland: on a Path between Discrimination and Integration. New York: Unicef, Innocenti Working Paper 2009-17.

Gabadinho, A. et al. (2011). Analyzing and Visualizing State Sequences in $\mathrm{R}$ with TraMineR. Journal of Statistical Software, 40, 1-37.

Ganzeboom, H. B. G., De Graaf, P. and Treiman, D. J. (with De Leeuw, J.) (1992). A standard international socio-economic index of occupational status. Social Science Research, 21, 1-56.

Gauthier, J. A. et al. (2009). How much does it cost? Optimization of costs in sequence analysis of social science data. Sociological Methods \& Research, 38, 197-231.

George, L. K. (1993). Sociological perspectives on life transitions. Annual Review of Sociology, 19, 353-373.

Giudici, F. and Gauthier, J. A. (2009). Différenciation des trajectoires professionnelles liées à la transition à la parentalité en Suisse. Revue Suisse de Sociologie, 35, 253-278.

Heath, A. F. and Brinbaum, Y. (2007). Guest editorial: explaining ethnic inequalities in educational attainment. Ethnicities, 7, 291-304.

Heath, A. and Cheung, S. (Eds.) (2007). Unequal Chances: Ethnic Minorities in Western Labour Markets. Proceedings of the British Academy, Oxford: Oxford University Press.

Heath, A., Rothon, C. and Kilpi, E. (2008). The secondgeneration in Western Europe: education, unemployment and educational attainment. Annual Review of Sociology, 34, 211-235.

Kalter, F., Granato, N. and Kristen, C. (2007). Disentangling recent trends of the second generation's structural assimilation in Germany. In Scherer, S., Pollack, R., Otte, G. and Gangl, M. (Eds.), From Origin to Destination: Trends and Mechanisms in Social Stratification Research. Frankfurt: Campus, pp. 214-245.

Karlson, K. and Holm, A. (2011). Decomposing primary and secondary effects: a new decomposition method. Research in Social Stratification and Mobility, 29, 221-237.

Kaufman, L. and Rousseeuw, P. J. (1990). Finding Groups in Data: An Introduction to Cluster Analysis. Hoboken, NJ: John Wiley \& Sons, Inc.

King, G. and Zeng, L. (2001). Logistic regression in rare events data. Political Analysis, 9, 137-163.

Kristen, C. and Granato, N. (2007). The educational attainment of the second-generation in Germany: Social Origins and Ethnic Inequality. Ethnicities, 7, 343-366. 
Laganà, F. et al. (2013). National minorities and their representation in social surveys: which practices make the difference? Quality \& Quantity, International Journal of Methodology, 47, 1287-1314.

Levels, M. and Dronkers, J. (2008). Educational performance of native and immigrant children from various countries of origin. Ethnic and Racial Studies, 31, 1404-1425.

Marks, G. (2005). Accounting for immigrant non-immigrant differences in reading and mathematics in twenty countries. Ethnic and Racial Studies, 28, 925-946.

Meyer, T. (2009). On ne prête qu'aux riches: L'inégalité des chances devant le système de formation en Suisse. In Suter, C., Perrenoud, S., Levy, R., Kuhn, U. et al. (Eds.), Rapport Social 2008. Zürich: Seismo, pp. 60-81.

Milligan, G. W. and Cooper, M. C. (1985). An examination of procedures for determining the number of clusters in a data set. Psychometrika, 50, 159-179.

OECD (2005). School factors related to quality and equity. Results from PISA 2000. Paris: OECD.

Phalet, K., Deboosere, P. and Bastiaenssen, V. (2007). Old and new inequalities in educational attainment: ethnic minorities in the Belgian Census 1991-2001. Ethnicities, 7, 390-415.

Piguet, E. (2004). L'immigration en Suisse. Cinquante ans d'entrouverture. Lausanne: Presses Polytechniques et Universitaires Romandes.

Portes, A. and Rumbaut, R. (2001). Legacies: the Story of Immigrant Second-Generation. Berkeley, CA: University of California Press and Russell Sage Foundation.

R Core Team (2011). R: A language and environment for statistical computing. $\mathrm{R}$ Foundation for Statistical Computing, Vienna, Austria. ISBN 3-900051-07-0.
Rothon, C. (2007). Can achievement differentials be explained by social class alone? An examination of minority ethnic educational performance in England and Wales at the end of compulsory schooling. Ethnicities, 7, 306-322.

Sacchi, S. (2008). The Construction of TREE Panel Weights. Documentation for the Eight Panel Waves from 2000 to 2007. Zurich: TREE.

Solon, G. (1992). Intergenerational Income Mobility in the United States. American Economic Review, 82, 393-408.

Stadelmann-Steffen, I. (2012). Education Policy and Educational Inequality - Evidence from the Swiss laboratory. European Sociological Review, 28, 379-393.

TREE (Ed.) (2010). Project Documentation 2000-2007. Basel: TREE.

Ward, J. H. (1963). Hierarchical grouping to optimize an objective function. Journal of the American Statistical Association, 58, 236-244.

van de Werfhorst, H. G. and van Tubergen, F. (2007). Ethnicity, schooling and merit in the Netherlands. Ethnicities, 7, 416-444.

Wingens, M. et al. (Eds.) (2011). A Life-Course Perspective on Migration and Integration. Dordrecht: Springer.

Winship, C. and Mare, R. D. (1984). Regression Models with Ordinal Variables. American Sociological Review, 49, 512-525.

Zeroulou, Z. (1988). La réussite scolaire des enfants d'immigrés: l'apport d'une approche en termes de mobilisation. Revue Française de Sociologie, 29, 447-470. 


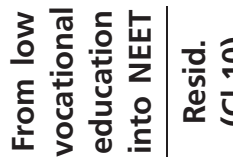

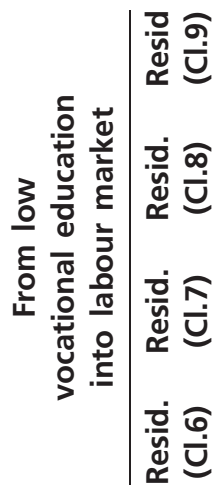

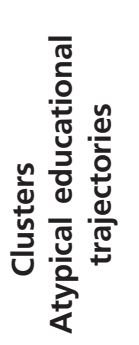

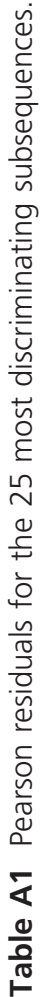

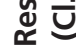
: ํํำ

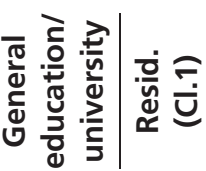

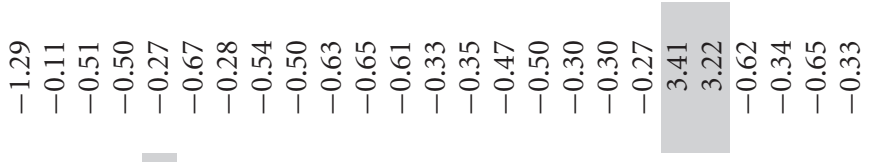

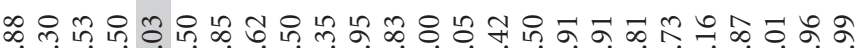
किं। मेंगें।

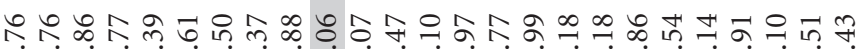
仵

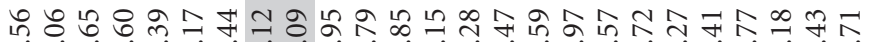
।

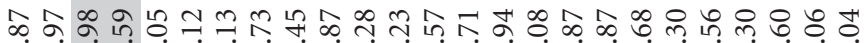
ím

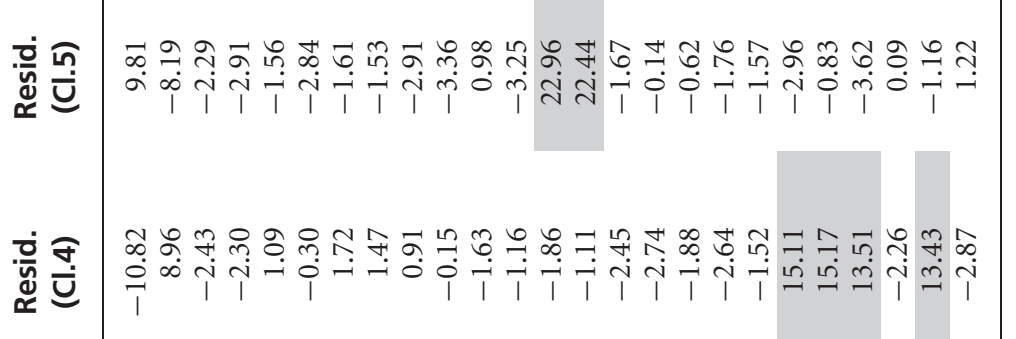

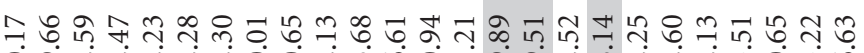

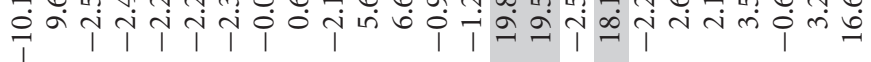

正 i ग

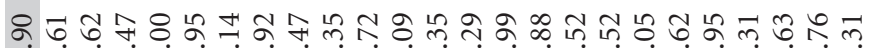

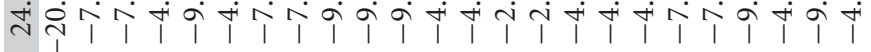

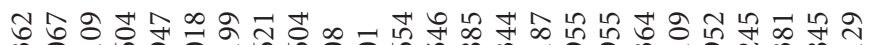

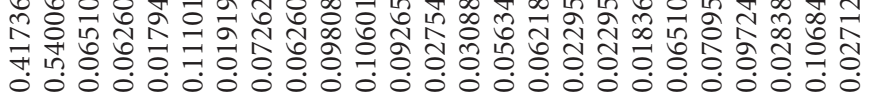

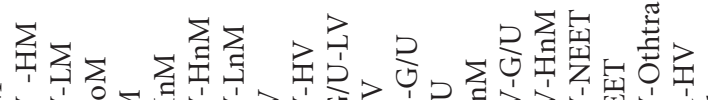

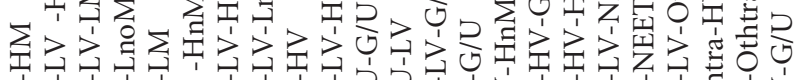

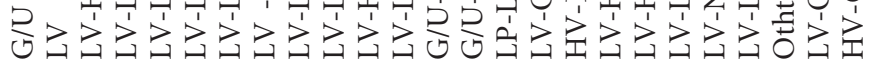




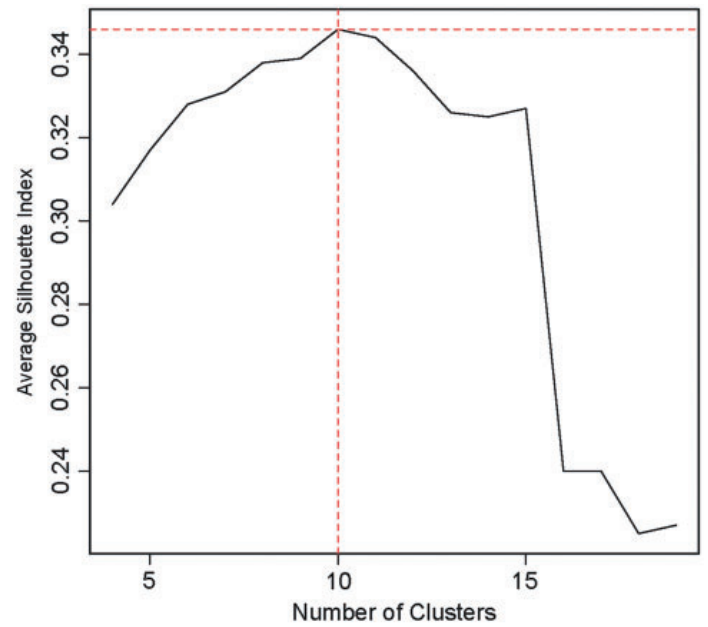

Figure A1 Average Silhouette Index distribution for the first 20 cluster solutions. Source: Our elaboration on TREE data. 